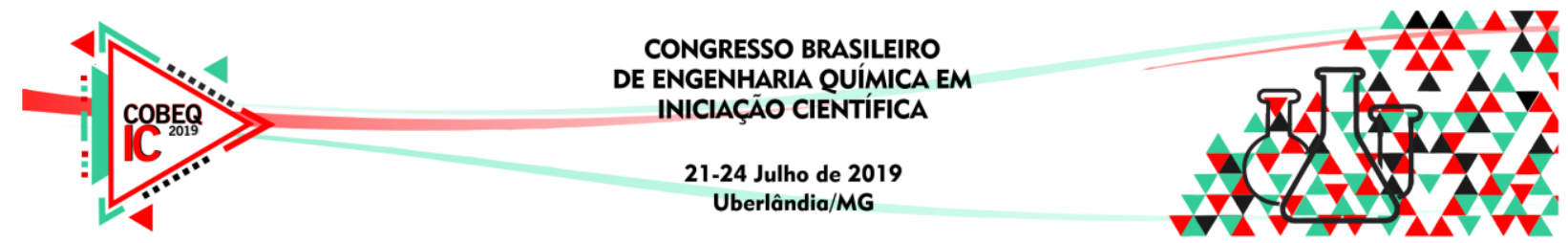

\title{
ESTUDO COMPARATIVO DO SECADOR POR ATOMIZAÇÃO E SECADOR EM LEITO DE JORRO NA SECAGEM DE POLPA DE PITANGA
}

\author{
A. B. M. LIMA ${ }^{1}$, E. M. O. PAIVA ${ }^{1}$, Y.S. ARAÚJO ${ }^{1}$, M. de F. D. de MEDEIROS ${ }^{1}$ \\ ${ }^{1}$ Universidade Federal do Rio Grande do Norte, Faculdade de Engenharia Química \\ E-mail para contato: mfatimadmedeiros@gmail.com
}

\begin{abstract}
RESUMO - Com o objetivo de se avaliar a secagem da polpa de pitanga com adição de leite fluido e outros adjuvantes em secador de leito de jorro e spray dryer, foram realizados ensaios de secagem, avaliando-se tanto as características do produto em pó como o desempenho dos dois secadores em relação ao rendimento da produção e eficiência térmica do processo. Análises físicoquímicas dos pós obtidos, tais como umidade, atividade de água, higroscopia e solubilidade foram realizadas. As eficiências foram muito baixas, o que pode ser justificado pela elevada vazão de ar requerida para manter a dinâmica dos dois secadores e às perdas de calor para o ambiente, visto que ambos os equipamentos não se encontravam termicamente isolados. Os adjuvantes interferiram positivamente no rendimento da produção com destaque para a albumina no leito de jorro e o Whey Protein para o spray.
\end{abstract}

\section{INTRODUÇÃO}

No presente trabalho estudou-se a secagem da polpa de pitanga (Eugenia uniflora L.), um fruto tropical nativo das regiões Sul e Sudeste do Brasil proveniente da pitangueira, espécie vegetal facilmente adaptada às condições climáticas da região Nordeste. A pitanga é pouco comercializada no Nordeste e por ser uma fruta muito perecível o desperdício de sua produção é elevado. Visando incentivar o crescimento de sua produção, mas consciente da necessidade de se evitar o desperdício da fruta in natura, pesquisas sobre o processamento e aproveitamento da pitanga vem sendo desenvolvidas pelo grupo de pesquisa em tecnologia de alimentos da UFRN.

A secagem por atomização ou spray é um dos métodos mais difundidos e utilizados desde o século XX na indústria alimentícia e também farmacêutica. Essa técnica consiste na atomização do líquido em uma câmara de secagem que recebe um fluxo constante de ar quente. Após o contato com o líquido, a água evapora instantaneamente. A grande vantagem desse método se deve ao fato de conservar as características nutricionais do produto, pois o tempo de contato com a fonte de calor é mínimo (Oliveira et al, 2006). Já o leito de jorro, segundo Araújo 2015, é contemplado por seus elevados coeficientes de transferência de calor e massa e distribuição de temperatura de secagem uniforme. Porém, a composição das frutas, rica em açúcares redutores pode inviabilizar esses processos de secagem, pois geram pós pegajosos que acarretam acúmulo de material no leito comprometendo a produção de pó. 


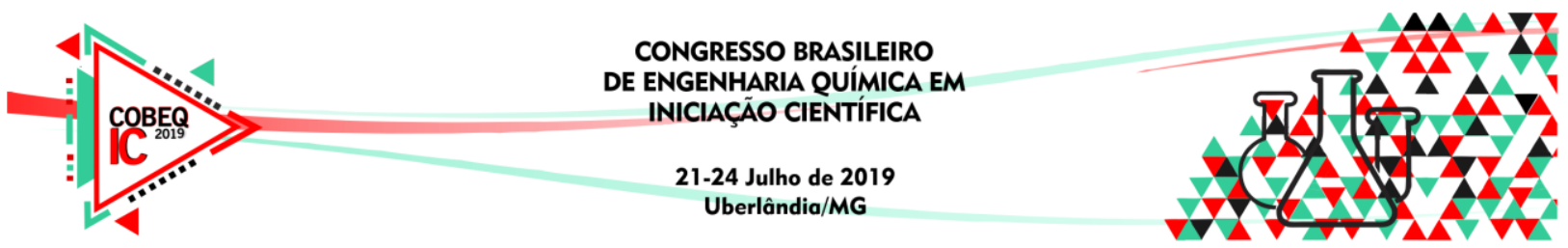

Para ambos os secadores a secagem de polpas de frutas só se torna viável com adição de adjuvantes que neutralizem os problemas de aderência do material no leito de partículas inertes para o caso do jorro e às paredes do secador para o spray. No presente trabalho investiga-se tanto a adição do leite como adjuvante de secagem, como de outros adjuvantes tais como a liga neutra, a albumina e o whey protein na secagem por atomização (spray), e em leito de jorro da polpa de pitanga, avaliando além das características dos pós produzidos nos dois secadores as eficiências de produção e energética dos mesmos

\section{METODOLOGIA EXPERIMENTAL}

\subsection{Materiais}

As misturas foram preparadas com polpa de pitanga da marca Delícia da Fruta adquirida congelada no mercado local e mantida nesta condição até sua utilização, leite fluido e adjuvantes: goma arábica (PLG), albumina (PLA) e whey protein (PLW). Os ingredientes foram pesados, misturados e homogeneizados através da agitação constante em liquidificador doméstico durante 1 minuto. Em todas as misturas foi mantida um percentual em massa de 60 $\%$ de polpa e $40 \%$ de leite, adicionando-se sobre o total $4 \%$ dos adjuvantes e foram preparadas $60 \%$ de polpa.

\subsection{Ensaios de Secagem}

O secador de leito de jorro, construído em aço inoxidável, é constituído por uma coluna cilíndrica ( $18 \mathrm{~cm}$ de diâmetro e $72 \mathrm{~cm}$ de altura) acoplada a uma base cônica (ângulo incluso $60^{\circ}, 13 \mathrm{~cm}$ de altura) com um orifício central $(3 \mathrm{~cm}$ de diâmetro), por onde é injetado a corrente de ar. Acoplado a coluna, tem-se um ciclone (10 cm de diâmetro da coluna) que promove a separação e coleta do pó. A alimentação do ar é feita por um soprador, acoplado na base cônica do secador e a formação do jorro se dá pela passagem do ar através das partículas, de tal forma que a circulação das partículas é iniciada quando a vazão do gás é suficiente para provocar o seu movimento ascendente. $\mathrm{O}$ ar é aquecido em um trocador de calor. A alimentação das misturas é realizada através de uma bomba peristáltica e ocorre de forma gotejante. Instrumentos de medição encontram-se instalados, tais como termopares para acompanhamento da temperatura do ar e da parede da coluna, termohigrômetro digital para medida da umidade relativa e temperatura do ar com precisão de $0,1 \%$ e $0,1{ }^{\circ} \mathrm{C}$ e um anemômetro digital, com precisão de $0,1 \mathrm{~m} / \mathrm{s}$ empregado para medir a velocidade do ar na saída do ciclone.

Neste trabalho utilizou-se como material inerte uma carga de partículas de $2500 \mathrm{~g}$ de polietileno de alta densidade com diâmetro médio igual a 3,2 $\pm 0,05 \mathrm{~mm}$ e densidade real de $0,875 \pm 0,468 \mathrm{~g} / \mathrm{cm} 3$. Em todos os ensaios, foram estabelecidas condições fixas de secagem. A vazão de alimentação foi aproximadamente $6,4 \mathrm{~mL} / \mathrm{min}$, gotejante e intermitente (6 minutos alimentando e 8 minutos parado), totalizando um tempo de secagem de 70 min com alimentação de $200 \mathrm{~g}$ da mistura. A velocidade e temperatura do ar na entrada do secador foi fixada em $29,3 \mathrm{~m} / \mathrm{s}$ e $70{ }^{\circ} \mathrm{C}$, respectivamente. O rendimento foi calculado como a razão entre as massas de pó produzida e da mistura alimentada, ambas expressas em base seca. 


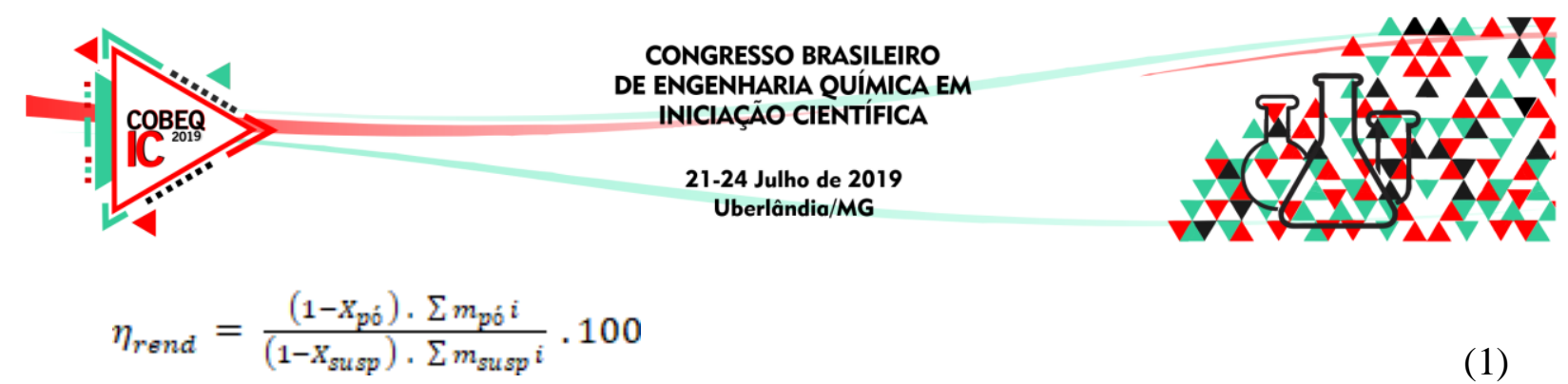

Na secagem em spray utilizou-se um spay dryer do fabricante LABMAQ DO BRASIL LMTD, modelo MSD 1. Para a operação foram fixados alguns parâmetros, como temperatura e vazão de ar de secagem de $120{ }^{\circ} \mathrm{C}$ e $1,65 \mathrm{~m} / \mathrm{min}$, respectivamente, vazão de ar de atomização do compressor de $0,35 \mathrm{~L} / \mathrm{min}$, vazão de alimentação da mistura de $\pm 0,68 \mathrm{~L} / \mathrm{h}$ com bico injetor de $1,2 \mathrm{~mm}$ de diâmetro, totalizando em média $355 \mathrm{~g}$ de mistura alimentado e um tempo de secagem de 35 minutos.

\subsection{Análises Físico-químicas}

Foram realizadas análise físico químicas para caracterização dos pós, determinando-se a umidade pelo método da estufa até peso constante, a atividade de água medida em analisador tipo AQUALAB, a higroscopia pelo método proposto por (CAI\& CORKE 2000), com algumas modificações de acordo com o estudo de Tonon et al. (2008). Para medir a solubilidade as amostras foram diluídas em proporção de $1 \mathrm{~g} / 100 \mathrm{~mL}$ e agitadas a $2500 \mathrm{rpm}$ por 5 minutos. Alíquotas do sobrenadante foram transferidas para secagem em estufa a 70 ${ }^{\circ} \mathrm{C}$ por 24 horas. A solubilidade foi calculada pela diferença entre o peso inicial e final do pesa filtro vezes 100 adicionado o peso do pó diluído, isso tudo dividido pela massa da amostra sobrenadante.

\subsection{Cálculo das Eficiências Térmicas}

A eficiência térmica foi definida pela razão entre à taxa de calor gasto na secagem e a taxa de calor fornecida pelo ar, conforme a Equação 2 (MACHADO, 2014).

$$
E_{f}=\frac{\text { Calor gasto na secagem }}{\text { Calor entrgue pelo ar }} .100
$$

A taxa de calor cedido pelo ar $\mathrm{Q}_{1}$ foi calculada através da Equação 3.

$$
Q_{1}=m_{a r} C p_{a r}\left(T_{\text {arentrada }}-T_{\text {arsaida }}\right)
$$

A taxa de calor gasto na secagem, $\mathrm{Q}_{2}$ foi definida como a taxa de calor necessária para aquecer a polpa e evaporar a água, podendo ser calculada através de um balanço de massa e energia. Através do balanço de massa em ambos os secadores se calculou a vazão de água evaporada e pela Equação 4 a taxa de calor, $Q_{2}$.

$$
Q_{2}=\dot{m}_{p o l p a} C p_{p o l p a}\left(T^{\prime} g_{s}-T_{a m b}\right)+m_{e v} \gamma^{T g s}
$$

Onde, $\dot{m}_{\text {polpa }}=$ vazão de polpa alimentada $(\mathrm{g} / \mathrm{s}),{ }^{C} p_{\text {polpa }}=$ calor específico da polpa alimentada $\left(\mathrm{J} / \mathrm{g} .{ }^{\circ} \mathrm{C}\right) ;{ }^{T} g_{s}=$ temperatura do gás na saída $\left({ }^{\circ} \mathrm{C}\right), m_{e v}=$ vazão mássica de água evaporada $(\mathrm{g} / \mathrm{s}) ; \gamma^{T g}=$ calor latente de vaporização da água na temperatura de saída $\left(\mathrm{J} / \mathrm{g} .{ }^{\circ} \mathrm{C}\right)$. 


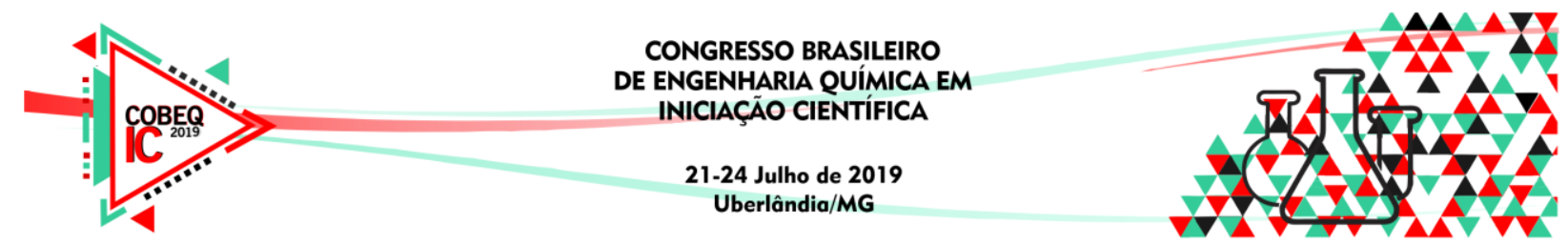

\section{RESULTADOS E DISCUSSÕES}

Conforme os resultados da Tabela 1, para o secador de leito de jorro a adição tanto da albumina como do whein protein promoveram maior produção de pó com rendimentos de $35,76 \%$ e $31,77 \%$, respectivamente. No spray dryer, a adição do whey protein promoveu o maior rendimento $(29,06 \%)$, seguido por rendimentos praticamente iguais quando foi adicionada a albumina e a goma arábica (aproximadamente $22 \%$ ).

Tabela 1 - Umidade e rendimento do processo

\begin{tabular}{cc|c|c|c|c|c} 
& \multicolumn{3}{c|}{ Spray Dryer } & \multicolumn{3}{c}{ Leito de Jorro } \\
\hline Amostras & PLG & PLW & PLA & PLG & PLW & PLA \\
\hline Umidade (\%) & 2,07 & 4,65 & 4,21 & 4,68 & 4,64 & 4,78 \\
\hline $\begin{array}{c}\text { Rendimento } \\
\text { (\%) }\end{array}$ & 21,7 & 29,1 & 22 & 14,4 & 31,8 & 35,8 \\
\hline
\end{tabular}

O melhor rendimento na secagem das misturas com albumina e whey pode ser explicado porque a introdução das proteínas na solução de alimentação promove a formação de um filme de proteção na interface ar-água das gotículas. Esse filme endurece quando em contato com ar seco, de modo que diminui a coalescência de gotículas bem como interações pegajosas das partículas na câmera de secagem do atomizador, (Bhandhari e Howes, 2015). Além disso, efeitos de difusividade também influenciam no aumento de recuperação do pó. Proteínas são moléculas de alto peso molecular e consequentemente de baixa difusividade, com isso tendem a permanecer na superfície das gotículas, enquanto frutose, sacarose e glicose, de maior difusividade, transferem-se para o centro da gotícula (Fang e Bandhari, 2012). Essas substâncias promovem a estabilização durante a secagem e podem também proteger os compostos sensíveis como os bioativos no pó seco (Moraes, 2014). O rendimento alcançado na secagem da polpa de pitanga com adição de leite e albumina é promissor, visto o baixo custo deste adjuvante frente ao da proteína isolada do soro do leite (whey protein).

Na Tabela 2, são apresentados os resultados referentes ao desempenho térmico dos ensaios de secagem realizados em leito de jorro e no spray dryer.

Tabela 2 - Eficiência Térmica

\begin{tabular}{ccc}
\hline & \multicolumn{2}{c}{ Eficiência Térmica (\%) } \\
\hline Amostras & Leito de Jorro & Spray Dyer \\
PLG & 20,91 & 22,63 \\
PLW & 20,51 & 24,44 \\
PLA & 21,30 & 26,67 \\
\hline Média & 20,91 & 24,58 \\
\hline
\end{tabular}

Conforme os resultados mostrados na Tabela 2, independentemente do tipo de secador as eficiências térmicas foram baixas e discretamente mais elevadas no spray, e podem ser 


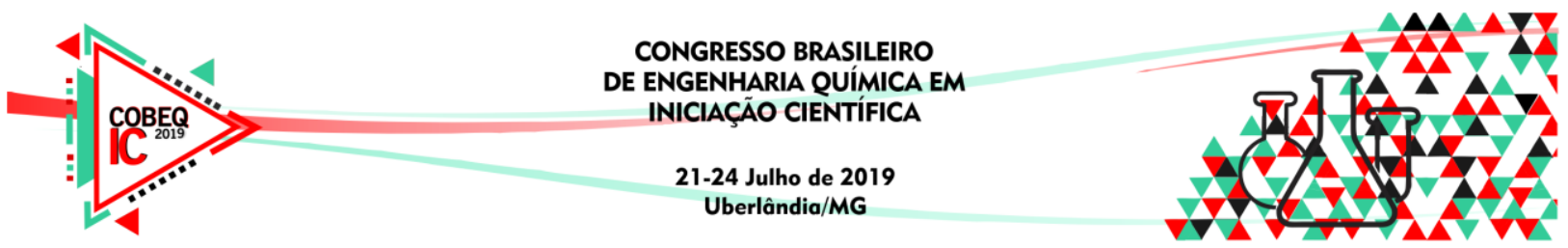

justificadas pela elevada vazão do ar requerida pelos secadores para manter as condições de secagem, principalmente o leito de jorro que precisa operar em condições superiores a vazão mínima necessária para manter as condições de jorro estável. Também é importante evidenciar que os secadores não se encontravam termicamente isolados, o que promove grandes perdas de calor para o ambiente.

Na Tabela 3, são ilustrados os resultados referentes a caracterização físico química dos pós. Conforme se observa, excetuando-se os experimentos realizados com adição da goma arábica no spray, a umidade dos pós apresentou valores em torno de 4,6 \%, todavia a atividade de água dos pós produzidos no jorro foi mais elevada e superior a 0,4. Em relação a higroscopia o comportamento se inverte, pós menos higroscópicos foram produzidos no jorro. Não se observou influência diferenciada dos adjuvantes na higroscopia dos pós. Comparando com a literatura (BORGES, 2015), a higroscopia do pó de pitanga com adição de $5 \%$ de goma arábica ficou torno de $17,18 \%$, mais elevada do que a obtida neste trabalho para o pó obtido no spray e no jorro, $14,66 \%$ e $7,72 \%$. Não se observa variação importante na solubilidade dos pós, 68,8 \% em média e inferiores ao valor encontrado por BORGES (2015) em torno de $84,12 \%$. Embora a adição de leite e adjuvantes tenha aumentado a concentração de sólidos solúveis na mistura, é possível se avaliar que a solubilidade sofreu o impacto do tratamento térmico.

Tabela 3 - Resultados referentes as análises físico-químicas

\begin{tabular}{c|c|c|c|c|c}
\hline Equipamento & \multicolumn{1}{c}{ Pós } & \multicolumn{1}{c}{ Higroscopia } & \multicolumn{1}{c}{ Umidade(\%) } & Solubilidade(\%) & Atividade de água \\
\hline \multirow{3}{*}{ Spray } & PLG & 14,89 & 2,07 & 68,78 & 0,293 \\
\cline { 2 - 6 } & PLA & 14,66 & 4,65 & 69,78 & 0,299 \\
\cline { 2 - 6 } & PLW & 12,59 & 4,21 & 62,43 & 0,293 \\
\hline \multirow{3}{*}{ Jorro } & PLG & 9,96 & 4,69 & 68,34 & 0,460 \\
\cline { 2 - 6 } & PLA & 7,72 & 4,78 & 59,43 & 0,423 \\
\cline { 2 - 6 } & PLW & 10,64 & 4,64 & 65,66 & 0,422 \\
\hline
\end{tabular}

\section{CONCLUSÃO}

Levando em consideração os resultados obtidos, o processo de secagem das misturas de polpa de pitanga com adição dos diferentes adjuvantes forneceram pós com características físico química semelhantes, com baixa higroscopia e solubilidade compatível com resultados citados na literatura como Machado (2014). A umidade e atividade de água inferiores a $5 \%$ e 0,47 indicam condições favoráveis a conservação e armazenamento. É importante ressaltar que a adição do leite e dos adjuvantes (proteína do leite, goma arábica, albumina), além de viabilizar o processo de secagem, aumenta o rendimento e minimiza as perdas de constituintes essenciais como os compostos bioativos e antioxidantes presentes nas polpas de frutas, ainda não avaliados no presente estudo, além de facilitar a produção de pós mais secos e mais estáveis sob o ponto de vista microbiológico. Em relação ao desempenho térmico, as eficiências foram muito baixas, o que pode ser justificado pela elevada vazão de ar requerida para manter a dinâmica dos dois secadores e as perdas de calor para o ambiente, visto que ambos os equipamentos não se encontravam termicamente isolados. Os estudos sobre a secagem de pitanga devem ser ampliados com vistas a melhorar o desempenho dos secadores, 


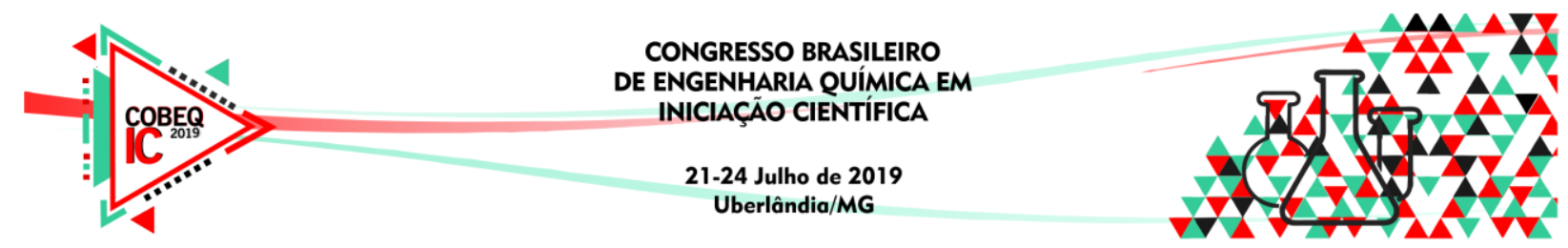

mediante a otimização das condições operacionais, minimização das perdas térmicas e reaproveitamento do potencial térmico do ar ainda muito aquecido que é liberado pelos secadores para o ambiente.

\section{REFERÊNCIAS}

ARAúJo, A. D. A., COElho, R. M. D. FOnTES, C. P. M. L, SilVA, A. R. A., COSTA, J. M. C. da RODRIGUES, S. Production and spouted bed drying of acerola juice contaming oligosaccharides. Food and Bioproducts Processing, v.94 p. 565-571, 2015.

BHANDARI, B.R.; HOWES, T. Relating the stickiness property of foods undergoing drying and dried products to their surface energetics. Drying Technology 2005, 23(4), 781-797.

BORGES, KÁTIA; Maria de Fátima Bezerra; Edilene souza da Silva; Patrícia Rocha; FUJITA, ALICE; GENOVESE, MARIA I.; Roberta Targino Pinto Correia. Fresh and spray dried pitanga (Eugenia uniflora) and jambolan (Syzygium cumini) pulps are natural sources of bioactive compounds with functional atributes, 2015.

CAI, Y. Z.; CORKE, H. Production and properties of spray-dried Amaranthus betacyanin pigments. Journal of Food Science, Chicago, v. 65, n. 6, p. 1248-1252, 2000 .

FANG, Z.; BHANDARI, B. Comparing the efficiency of protein and maltodextrin on spray drying of bayberry juice. Food Research International, v. 48, p. 478-483, 2012.

JAYASUNDERA, M., ADHIKARI, B., ADHIKARI, R., ALDRED, P. The effect of protein types and low molecular weight surfactants on spray drying of sugar-rich foods. Food Hydrocolloids, v. 25, 459-469, 2011.

MACHADO, I. P. Avaliação térmica e desempenho do processo de secagem de misturas de graviola e leite em secador de leito de jorro. 91f Dissertação. Pós-graduação em Engenharia química. Universidade Federal do rio grande do Norte. 2014.

MORAES, Francisca Pereira de. Polpa desidratada de caju amarelo (Anacardium Occidentale l.) por atomização em spray dryer: caracterização físico - química, bioativa e estudo da vida de prateleira do produto. 2014. 140 f. Dissertação (Mestrado) - Curso de Engenharia Química, Universidade Federal do Rio Grande do Norte, Natal, 2014.

OLIVEIRA, F.M.N.; FIGUEIRÊDO, R,M.F.; QUEIROZ,A.J.M. Análise comparativa de polpas de pitanga integral, formulada e em pó. Revista Brasileira de Produtos Agroindustriais, v.8, p.25-33, 2006.

TONON, R. V.; BRABET, C.; HUBINGER, M. D. Influence of process conditions on the physicochemical properties of açaí (Euterpe oleraceae Mart.) powder produced by srapy drying. Journal of Food Engineering, Oxford, v. 88, n. 3, p. 411-418, 2008. 